\title{
Karakteristik Kwetiau dari Tepung Beras yang Dicampur Tepung Umbi Uwi (Dioscorea alata), Talas (Colocasia esculenta) dan Kimpul (Xanthosoma sagittifolium) Termodifikasi \\ Characteristics of Kwetiau from Rice Flour Mixed with Yam (Dioscorea alata), Taro \\ (Colocasia esculenta) and Cocoyam (Xanthosoma sagittifolium) Modified Flour
}

\author{
Muflihah Ramadhia, Ledy Purwandani, Erning Indrastuti* \\ Jurusan Teknologi Pertanian, Politeknik Negeri Pontianak, Pontianak, Indonesia \\ *Correspondence Author: indrastuti_erning@yahoo.com
}

\begin{abstract}
ABSTRAK
Tepung umbi uwi (Dioscorea alata), talas (Colocasia esculenta (L) Schott) dan kimpul (Xanthosoma sagittifolium (L) Schott), yang telah dimodifikasi HMT diaplikasikan dalam pembuatan kwetiau. Tujuan penelitian ini untuk mengetahui pengaruh pencampuran tepung uwi, talas, dan kimpul termodifikasi HMT dan tepung beras terhadap karakteristik kwetiau. Proporsi tepung beras: tepung umbi $75: 25 \% ; 50: 50 \% ; 25: 75 \% ; 0: 100 \%$ dan tepung beras $100 \%$ sebagai kontrol. Proporsi tepung umbi termodifikasi dan tepung beras berpengaruh terhadap karakteristik kwetiau tetapi tidak mempengaruhi kadar air kwetiau. Kwetiau dari tepung beras $100 \%$ (kontrol) memiliki waktu pemasakan, berat rehidrasi dan susut masak paling kecil, daya patah, daya putus dan elastisitas tinggi. Kwetiau yang mendekati karakteristik kwetiau beras adalah kwetiau dari tepung talas $100 \%$.
\end{abstract}

Kata Kunci: Heat Moisture Treatment, Kimpul, Talas, Uwi.

\section{ABSTRACT}

Modification of yam (Dioscorea alata), taro (Colocasia esculenta (L) Schott) and cocoyam (Xanthosoma sagittifolium (L) Schott) by Heat Moisture Treatment (HMT), were applied to produce kwetiau. The purpose of this study was to investigate the effect of mixing yam, taro and cocoyam flour modified HMT and rice flour on the characteristics of kwetiau. The proportion of rice flour: modified tuber flour modified tuber flour 75: 25\%; 50: $50 \%$; 25 : 75\%; 0: $100 \%$ and $100 \%$ rice flour as a control. The proportion of modified tuber flour and rice flour influences the characteristics of noodles but does not affect the water content of noodles. Rice noodles from rice flour $100 \%$ (control) have the lowest cooking time, rehydration weight and cooking loss, breaking strength, breaking strength and high elasticity. Rice noodles that are close to the characteristics of rice noodles are rice noodles from $100 \%$ modified taro flour.

Keyword: Heat Moisture Treatment, Cocoyam, Taro, Yam

\section{PENDAHULUAN}

Umbi uwi atau keribang/ubi kelapa (Dioscorea alata), talas atau keladi (Colocasia esculenta (L) Schott) dan kimpul atau keladi sarawak/talas belitung (Xanthosoma sagittifolium (L) Schott) merupakan bagian dari umbi lokal yang tumbuh di Kalimantan Barat, berpotensi sebagai sumber karbohidrat. Rais (2004) mengidentifikasi 6 jenis uwi dan 15 jenis talas-talasan di Kalimantan Barat. Umbi- umbian tersebut belum banyak pemanfaatannya sehingga perlu penelitian untuk diversifikasinya. Salah satu pemanfaatan umbi yaitu diolah menjadi tepung dan digunakan sebagai pengganti tepung beras dalam pembuatan kwetiau.

Kwetiau adalah mie yang berbentuk pipih yang terbuat dari tepung beras dan air tetapi kadang-kadang ditambahkan tapioka dan pati lain untuk meningkatkan transparansi atau meningkatkan kelengketan dan tekstur kenyal mie (Ismail 
et al., 2016). Kwetiau memerlukan bahan baku tepung beras yang mengandung pati dengan amilosa tinggi misalnya varietas Chai Nat I yang mempunyai kadar amilosa lebih dari $27 \%$ (Cham and Suwannaporn, 2010; Phothiset and Charoenrein, 2006). Pati dengan amilosa tinggi cenderung mudah mengalami retrogradasi (Wattanachant et al., 2002). Kecepatan pati untuk mengalami retrogradasi dibutuhkan untuk membentuk tekstur pada saat mie didinginkan. Mie juga memerlukan bahan baku dengan pati dengan sifat amilografi yang membentuk kurva tipe $\mathrm{C}$ yaitu tidak memiliki puncak viskositas namun viskositas cenderung tinggi dan tidak mengalami penurunan selama pemanasan dan pengadukan (Lii and Chang, 1981), sehingga menghasilkan bihun yang tidak lengket.

Pengolahan umbi uwi, talas dan kimpul menjadi tepung lebih mudah dibandingkan dengan pati, karena umbi-umbian tersebut mengandung lendir (Huang et al., 2010) yang menyebabkan terhambatnya pemisahan pati dari komponen lain saat pengendapan.

Permasalahannya penggunaan tepung umbi asli diduga akan menghasilkan kwetiau yang kurang memuaskan. Sifat tepung alami yang kurang sesuai diharapkan dapat diperbaiki dengan modifikasi pati, diantaranya dengan Heat Moisture Treatment (HMT). Kwetiau hasil pencampuran tepung beras dan tepung umbi termodifikasi HMT belum diketahui karakteristiknya sehingga diperlukan penelitian mengenai karakteristik kwetiau yang dihasilkan.

\section{BAHAN DAN METODE}

Bahan yang dipergunakan dalam penelitian ini adalah umbi uwi/keribang, umbi talas/keladi, umbi kimpul/keladi sarawak yang telah mengalami proses modifikasi dengan metode HMT hasil penelitian tahap I (Purwandani, Indrastuti, Ramadhia, 2014). Tepung termodifikasi HMT yang digunakan adalah tepung uwi dari kombinasi perlakuan kadar air 30\% dan lama perlakuan HMT 4 jam (T1), tepung talas dari kombinasi perlakuan kadar air $20 \%$ dan lama perlakuan 4 jam (T2), tepung kimpul dari kombinasi perlakuan kadar air $30 \%$ dan lama perlakuan 10 jam (T3). Pembuatan kwetiau dengan tepung beras yang dicampur dengan masing-masing tepung uwi, talas dan kimpul termodifikasi HMT. Proporsi tepung beras : tepung umbi $=100: 0 \% ; 75$ : 25\%; 50 : 50\%; 25 : 75\%; 0 : 100\%. Tepung dengan proporsi yang telah ditetapkan dicampur dengan air untuk mendapatkan perbandingan tepung dan air $1: 2$ (b/b), sehingga membentuk bubur tepung. Bubur tepung kemudian disetimbangkan selama 1 jam, kemudian dituang pada loyang secara merata, dikukus selama 5 menit sehingga tergelatinisasi, dan didinginkan ke suhu kamar. Lembaran kwetiau dipotong dengan lebar $1 \mathrm{~cm}$ dan dikeringkan sampai mencapai kadar air 10\%. Pembuatan kwetiau ini mengacu pada metode Cham and Suwannaporn (2010).

Pengujian karakteristik kwetiau meliputi kadar air (AOAC, 2005), analisis tekstur (dengan texture analyzer), waktu pemasakan (cooking time), susut masak (cooking loose) dan berat rehidrasi (Fari et al., 2011). Data hasil pengamatan kwetiau tiga kali ulangan dianalisis dengan menggunakan ANOVA metode Rancangan Acak Kelompok dan Duncan's multiplerange tests menggunakan SPSS.

\section{HASIL DAN PEMBAHASAN}

\section{Bahan Baku}

Bahan baku kwetiau yang digunakan adalah tepung umbi hasil modifikasi HMT terbaik pada penelitian tahap I sedangkan tepung beras yang digunakan adalah tepung beras komersial. Hasil analisis sifat fisikokimia bahan baku disajikan pada Tabel 1.

\section{Kadar air}

Perlakuan subtitusi tepung beras dan tepung umbi termodifikasi tidak berpengaruh nyata terhadap kadar air (Tabel 1). Selama pengeringan, air pada permukaan mie menguap dan menyebabkan gradien kadar air dan air dari dalam berdifusi ke permukaan mie (Fu, 2008). 
Tabel 1. Rerata Sifat Fisikokimia Tepung Uwi, Talas dan Kimpul termodifikasi HMT dan tepung beras

\begin{tabular}{lcccc}
\hline Parameter & Tepung Uwi & $\begin{array}{c}\text { Tepung } \\
\text { Talas }\end{array}$ & $\begin{array}{c}\text { Tepung } \\
\text { Kimpul }\end{array}$ & $\begin{array}{c}\text { Tepung } \\
\text { Beras }\end{array}$ \\
\hline Kadar Air (\%) & 13,43 & 13,60 & 17,20 & 12,83 \\
Kadar Amilosa (\%) & 29,61 & 13,94 & 26,57 & 23,86 \\
Swelling Power & 9,11 & 4,43 & 3,93 & 4,45 \\
Kelarutan & 2,04 & 4,66 & 3,59 & 4,32 \\
Waktu Awal Gelatinisasi (menit) & 15 & 14,67 & 15,33 & 12,34 \\
Suhu Awal Gelatinisasi $\left({ }^{\circ} \mathrm{C}\right)$ & 85,77 & 82,50 & 85,10 & 83,72 \\
Waktu Gelatinisasi (menit) & td & td & td & 9,8 \\
Suhu Gelatinisasi $\left({ }^{\circ} \mathrm{C}\right)$ & td & td & td & 76,3 \\
Viskositas Puncak $(\mathrm{cP})$ & td & td & td & 2184 \\
Viskositas Panas $(\mathrm{cP})$ & td & td & td & 1668 \\
Viskositas Final (cP) & 935,33 & 1154,33 & 1150,37 & 3384 \\
\hline
\end{tabular}

Keterangan: $\mathrm{td}=$ tidak terdapat data

Tabel 2. Rerata Kadar Air, Waktu Pemasakan, Berat Rehidrasi dan Susut Masak Kwetiau akibat Pengaruh Proporsi Tepung Beras dan Tepung Umbi Termodifikasi

\begin{tabular}{lccccc}
\hline \multicolumn{1}{c}{ Perlakuan } & $\begin{array}{c}\text { Proporsi } \\
(\%)\end{array}$ & $\begin{array}{c}\text { Kadar Air } \\
(\%)\end{array}$ & $\begin{array}{c}\text { Waktu } \\
\text { Pemasakan } \\
\text { (menit) }\end{array}$ & $\begin{array}{c}\text { Berat Rehidrasi } \\
(\%)\end{array}$ & $\begin{array}{c}\text { Susut Masak } \\
(\%)\end{array}$ \\
\hline Tepung beras & 100 & $7.54 \pm 0,57$ & $3,16 \pm 0,17 \mathrm{a}$ & $229,51 \pm 3,92 \mathrm{~b}$ & $32,17 \pm 0,96 \mathrm{~h}$ \\
& $25: 75$ & $8.96 \pm 0,85$ & $5,63 \pm 0,12 \mathrm{fg}$ & $240,95 \pm 20,14 \mathrm{c}$ & $23,35 \pm 0,12 \mathrm{a}$ \\
Tepung uwi: beras & $50: 50$ & $8.46 \pm 0,16$ & $7,69 \pm 0,11 \mathrm{j}$ & $224,24 \pm 28,79 \mathrm{~b}$ & $26,41 \pm 0,29 \mathrm{de}$ \\
& $75: 25$ & $8.77 \pm 0,75$ & $6,45 \pm 0,13 \mathrm{i}$ & $225,53 \pm 5,62 \mathrm{~b}$ & $25,25 \pm 0,06 \mathrm{c}$ \\
& $100: 0$ & $8.88 \pm 0,54$ & $4,86 \pm 0,17 \mathrm{e}$ & $233,46 \pm 17,41 \mathrm{bc}$ & $22,84 \pm 0,39 \mathrm{a}$ \\
Tepung talas: beras & $25: 75$ & $8.05 \pm 0,35$ & $3,94 \pm 0,06 \mathrm{~d}$ & $265,64 \pm 7,68 \mathrm{e}$ & $27,64 \pm 0,43 \mathrm{~g}$ \\
& $50: 50$ & $7.85 \pm 0,25$ & $3,78 \pm 0,10 \mathrm{c}$ & $249,45 \pm 8,39 \mathrm{~d}$ & $28,16 \pm 0,64 \mathrm{~g}$ \\
& $75: 25$ & $7.55 \pm 0,32$ & $3,42 \pm 0,11 \mathrm{~b}$ & $227,63 \pm 9,58 \mathrm{~b}$ & $28,05 \pm 0,13 \mathrm{~g}$ \\
& $100: 0$ & $7.67 \pm 0,43$ & $3,06 \pm 0,08 \mathrm{a}$ & $208,42 \pm 7,38 \mathrm{a}$ & $26,52 \pm 0,36 \mathrm{e}$ \\
Tepung kimpul: beras & $25: 75$ & $8.48 \pm 0,89$ & $5,53 \pm 0,13 \mathrm{f}$ & $268,09 \pm 5,62 \mathrm{e}$ & $26,04 \pm 0,91 \mathrm{~d}$ \\
& $50: 50$ & $8.03 \pm 0,69$ & $5,04 \pm 0,18 \mathrm{~h}$ & $286,49 \pm 7,25 \mathrm{f}$ & $26,96 \pm 0,57 \mathrm{ef}$ \\
& $75: 25$ & $7.89 \pm 0,85$ & $5,69 \pm 0,16 \mathrm{~g}$ & $245,49 \pm 5,88 \mathrm{c}$ & $27,48 \pm 1,08 \mathrm{fg}$ \\
& $100: 0$ & $8.90 \pm 0,64$ & $4,89 \pm 0,11 \mathrm{e}$ & $270,96 \pm 9,65 \mathrm{e}$ & $24,21 \pm 0,71 \mathrm{~b}$ \\
\hline
\end{tabular}

Keterangan : Angka rerata yang diikuti dengan huruf yang sama pada kolom yang sama tidak berbeda nyata pada uji Duncan $\alpha=0,05$

Waktu dan suhu pengeringan yang digunakan sama untuk semua perlakuan yaitu waktu pengeringan 9 jam dan suhu pengeringan $70^{\circ} \mathrm{C}$, pada kondisi ini kadar air kwetiau sudah mencapai kesetimbangan dengan lingkungan sehingga kwetiau yang dikeringkan memiliki kadar air yang tidak berbeda.

\section{Kualitas Masak.}

Kualitas masak terdiri dari waktu pemasakan, berat rehidrasi dan susut masak. Proporsi tepung beras dan tepung umbi termodifikasi HMT memberikan pengaruh yang sangat nyata terhadap waktu pemasakan, berat rehidrasi dan susut masak kwetiau $(P<0,05)$ seperti yang disajikan pada Tabel 2.

Waktu pemasakan berkisar 3,06-7,69 menit, sebanding dengan mie beras dari penelitian Bhattacharya et al. (1999) yang berkisar $4-5$ menit. Waktu pemasakan bertambah dengan semakin banyak proporsi tepung umbi uwi dan kimpul, tetapi terjadi sebaliknya pada tepung talas dimana semakin besar proporsi tepung talas waktu pemasakan semakin menurun. Suhu awal gelatinisasi tepung talas paling rendah disusul tepung beras, tepung kimpul dan tepung uwi, hal ini sesuai dengan pernyataan Qazi et al. (2014) waktu pemasakan dipengaruhi oleh suhu gelatinisasi. Menurut Fari et al. (2011) 
waktu pemasakan pada mie beras harus singkat dengan kehilangan padatan dalam air rebusan yang rendah dan rehidrasi yang rendah biasanya menghasilkan mie dengan tekstur kasar dan keras, waktu pemasakan yang terlalu tinggi menyebabkan mie terlalu lunak dan lengket.

Berat rehidrasi adalah persentase kenaikan berat mie setelah dimasak dibandingkan dengan berat mie kering (Thomas et al., 2014). Kwetiau memliki berat rehidrasi antara 208,42 - 286,49\% yang sebanding dengan mie beras hasil penelitian Bhattacharya et al. (1999) yaitu 248,3 - 296\%, hal ini menunjukkan kwetiau menunjukkan toleransi masak yang baik Berat rehidrasi kwetiau dari tepung uwi tidak berbeda nyata dengan kwetiau dari beras $100 \%$ (kontrol) dan relatif rendah dibandingkan dengan kwetiau dari tepung talas dan kimpul pada penambahan tepung beras yang sama, hal ini disebabkan viskositas final tepung uwi yang lebih rendah dibandingkan dengan viskositas final tepung talas dan kimpul. Menurut Bhattacharya at al. (1999) berat rehidrasi berkorelasi positif dengan viskositas final. Pada pati dengan viskositas final tinggi maka terjadi retrogradasi pati yang cepat sehingga dapat membatasi hidrasi air. Retrogradasi pati, yaitu bergabungnya rantai molekul amilosa yang berdekatan melalui ikatan hidrogen intermolekul (Alcázar-Alay and Meireles, 2015). Retrogradasi pati terutama disebabkan oleh molekul amilosa, karena pembentukan ikatan hidrogen antar molekul amilosa lebih mudah terbentuk, sehingga semakin banyak fraksi amilosa yang keluar dari granula selama proses gelatinisasi, semakin banyak pati teretrogradasi yang terbentuk (Srichuwong et al., 2005).

Berat rehidrasi kwetiau dari tepung uwi, tepung talas dan tepung kimpul termodifikasi HMT semakin menurun dengan bertambahnya tepung uwi, talas dan kimpul, hal ini karena tepung beras mempunyai viskositas final dan setback yang tinggi dibandingkan dengan semua tepung umbi termodifikasi HMT.

Susut masak didefinisikan sebagai massa padatan hilang ke air selama perebusan (Ugarčić-Hardi et al., 2007).
Susut masak yang tinggi tidak diharapkan karena menunjukkan kelarutan pati yang tinggi, air rebusan menjadi keruh, berkurangnya padatan dan rasa lengket di mulut (Thomas et al., 2014). Susut masak tepung beras $100 \%$ menunjukkan nilai tertinggi di antara semua perlakuan. Semakin besar penambahan tepung uwi dan tepung kimpul maka susut masak semakin kecil. Tepung uwi dan tepung kimpul mempunyai kadar amilosa yang lebih tinggi dibandingkan dengan tepung beras. Semakin besar penambahan tepung uwi dan kimpul maka kadar amilosa adonan semakin besar, kadar amilosa yang besar menyebabkan susut masak yang rendah. Pada penambahan tepung umbi yang sama, kwetiau dari tepung uwi mempunyai susut masak lebih kecil dibandingkan dengan kwetiau dari tepung kimpul dan kwetiau dari tepung kimpul mempunyai susut masak yang lebih kecil dari tepung talas. Tepung uwi mempunyai kadar amilosa yang lebih besar dari tepung kimpul dan tepung kimpul mempunyai kadar amilosa lebih besar dari tepung talas. Hasil ini sesuai dengan penelitian Chen (2003) dan Thao and Noomhorm (2011) yaitu susut masak berkorelasi negatif dengan kadar amilosa.

Susut masak kwetiau perlakuan subtitusi tepung talas $25,50,75$ dan $100 \%$ tidak menunjukan perbedaan nyata, hal ini karena tepung talas mempunyai kadar amilosa yang kecil dibandingkan dengan tepung beras. Kadar amilosa tepung beras mempunyai pengaruh yang lebih besar dalam menentukan susut masak mie dari tepung talas.

\section{Sifat Tekstur}

Sifat tekstur kwetiau yaitu daya patah kwetiau sebelum pemasakan dan daya putus serta elastisitas kwetiau setelah pemasakan adalah karakteristik yang penting, yang menentukan penerimaan konsumen (Fari et al., 2011). Hasil analisis ragam menunjukkan bahwa perlakuan proporsi tepung beras dan tepung umbi termodifikasi HMT memberikan pengaruh yang sangat nyata $(p<0.05)$ terhadap daya patah, daya putus dan elastisitas kwetiau. Rerata daya patah, daya putus dan elastisitas kwetiau akibat pengaruh 
proporsi tepung beras dan tepung umbi termodifikasi disajikan pada Tabel 3. Daya patah paling tinggi pada kwetiau dari tepung beras $100 \%$. Kwetiau dari tepung beras $100 \%$ memerlukan gaya yang besar untuk patah atau kwetiau tersebut tidak mudah patah. Daya patah kwetiau semakin besar dengan semakin besar proposi tepung uwi dan tepung kimpul. tetapi menurun pada kwetiau dari tepung uwi dan kimpul $100 \%$. Peningkatan daya patah disebabkan peningkatan kadar amilosa dengan meningkatnya tepung uwi dan tepung kimpul, hal ini sesuai dengan penelitian Fari et al. (2011), yaitu kekuatan mie berkorelasi positif dengan kadar amilosa.

Amilosa dan amilopektin, keduanya terlibat dalam proses retrogradasi. Kwetiau dari tepung dengan amilosa tinggi mudah mengalami retrogradasi. Amilosa mengalami retrogradasi yang cepat, berlangsung selama beberapa jam, sedangkan retrogradasi amilopektin membutuhkan waktu lebih lama (AlcázarAlay and Meireles, 2015). Menurut RindlavWestling et al. (1998), rantai linear dari amilosa dalam larutan lebih berinteraksi dengan ikatan hidrogen akibatnya, amilosa gel dan film lebih keras dan lebih kuat dari gel amilopektin film.

Tabel 3. Rerata Daya Patah, Daya Putus dan Elastisitas Kwetiau Akibat Pengaruh Proporsi Tepung Beras dan Tepung Umbi Termodifikasi

\begin{tabular}{cccll}
\hline Perlakuan & Proporsi (\%) & Daya Patah $(\mathrm{N})$ & \multicolumn{1}{c}{ Daya Putus $(\mathrm{N})$} & \multicolumn{1}{c}{ Elastisitas (\%) } \\
\hline Tepung umbi: beras & 100 & $13.40 \pm 1,06 \mathrm{~g}$ & $4.27 \pm 0,42 \mathrm{e}$ & $32.33 \pm 2,03 \mathrm{f}$ \\
& $25: 75$ & $7.43 \pm 0,78 \mathrm{c}$ & $2.00 \pm 0,30 \mathrm{bc}$ & $23.33 \pm 3,34 \mathrm{de}$ \\
Tepung uwi : beras & $50: 50$ & $7.10 \pm 0,70 \mathrm{c}$ & $0.97 \pm 0,06 \mathrm{a}$ & $21.11 \pm 1,92 \mathrm{~cd}$ \\
& $75: 25$ & $11.30 \pm 0,90 \mathrm{f}$ & $1.03 \pm 0,06 \mathrm{a}$ & $15.56 \pm 1,93 \mathrm{ab}$ \\
& $100: 0$ & $4.20 \pm 0,40 \mathrm{a}$ & $0.97 \pm 0,12 \mathrm{a}$ & $14.44 \pm 1,93 \mathrm{a}$ \\
& $25: 75$ & $8.23 \pm 0,65 \mathrm{c}$ & $2.13 \pm 0,25 \mathrm{c}$ & $17.78 \pm 1,92 \mathrm{bc}$ \\
Tepung talas : beras & $50: 50$ & $4.93 \pm 0,65 \mathrm{ab}$ & $2.20 \pm 0,30 \mathrm{c}$ & $21.10 \pm 1,91 \mathrm{~cd}$ \\
& $75: 25$ & $5.17 \pm 0,68 \mathrm{~b}$ & $3.03 \pm 0,35 \mathrm{~d}$ & $22.20 \pm 1,91 \mathrm{~d}$ \\
& $100: 0$ & $9.30 \pm 0,85 \mathrm{~d}$ & $3.03 \pm 0,42 \mathrm{~d}$ & $25.56 \pm 1,93 \mathrm{e}$ \\
Tepung kimpul : beras & $25: 75$ & $10.17 \pm 0,93 \mathrm{e}$ & $2.00 \pm 0,20 \mathrm{bc}$ & $32.10 \pm 1,83 \mathrm{f}$ \\
& $50: 50$ & $11.87 \pm 0,59 \mathrm{f}$ & $2.07 \pm 0,21 \mathrm{c}$ & $25.56 \pm 1,93 \mathrm{e}$ \\
& $75: 25$ & $9.60 \pm 0,72 \mathrm{de}$ & $2.97 \pm 0,31 \mathrm{~d}$ & $23.32 \pm 3,34 \mathrm{de}$ \\
& $100: 0$ & $3.63 \pm 0,15 \mathrm{a}$ & $1.73 \pm 0,25 \mathrm{~b}$ & $14.44 \pm 1,93 \mathrm{a}$ \\
\hline
\end{tabular}

Keterangan : Angka rerata yang diikuti dengan huruf yang sama pada kolom yang sama tidak berbeda
Penurunan daya patah pada kwetiau dari tepung uwi $100 \%$ karena kadar amilosa terlalu tinggi, sehingga pada waktu dan suhu gelatinisasi kwetiau tersebut belum tergelatinisasi sempurna. Kwetiau dari tepung uwi $100 \%$ secara visual memiliki penampakan yang kurang bening atau masih terdapat spot putih yang menandakan tepung belum tergelatinisasi sempurna. Pada kwetiau yang dengan penambahan tepung talas tidak menunjukkan pola yang teratur.

Daya putus tertinggi pada kwetiau dari tepung beras 100\%, kwetiau ini memerlukan gaya yang paling besar untuk putus atau kwetiau tidak mudah putus. Daya putus semakin rendah dengan semakin besar proporsi tepung uwi dan tepung kimpul, hal ini disebabkan berat rehidrasi kwetiau yang lebih besar dibandingkan kwetiau dari beras $100 \%$. Berat rehidrasi yang besar menyebabkan kwetiau menjadi lunak dan mudah putus (Fari et al., 2011). Daya putus kwetiau semakin besar dengan bertambahnya proporsi tepung talas, hal ini akibat berat rehidrasi kwetiau semakin kecil, sehingga kwetiau berkurang kelunakaannya dan kwetiau tidak mudah putus.

\footnotetext{
nyata pada uji Duncan $\alpha=0,05$
} 
Elastisitas menunjukkan pemanjangan bahan jika ditarik dengan gaya tertentu. Persen elastisitas diperoleh dari persentase penambahan panjang sampai batas putus dengan panjang awal kwetiau (Ahmed et al., 2016). Elastisitas tertinggi pada kwetiau dari tepung beras $100 \%$, kwetiau ini tidak mudah putus saat diberikan gaya tertentu. Elastisitas kwetiau semakin rendah dengan semakin besar proporsi tepung uwi dan tepung kimpul. Sebaliknya, elastisitas kwetiau semakin besar dengan bertambahnya proporsi tepung talas. Elastisitas pada kwetiau sesuai dengan daya putus kwetiau setelah rehidrasi, hal ini sesuai dengan penelitian Fari et al. (2011) yaitu uji tarik atau daya putus dan elastisitas berkorelasi satu dengan yang lain.

Elastisitas kwetiau berhubungan dengan berat rehidrasi. Penurunan elastisitas pada kwetiau yang disubtitusi tepung uwi dan tepung kimpul diakibatkan berat rehidrasi kwetiau yang lebih besar dibandingkan kwetiau dari beras 100\%. Berat rehidrasi yang besar menyebabkan kwetiau menjadi lunak, mudah putus dan tidak elastis (Fari et al., 2011). Peningkatan elastisitas pada kwetiau dengan semakin besar proporsi tepung talas akibat menurunnya berat rehidrasi kwetiau, sehingga kwetiau berkurang kelunakaannya dan kwetiau semakin elastis.

\section{KESIMPULAN}

Proporsi tepung beras dan tepung umbi uwi, talas dan kimpul yang telah dimodifikasi HMT tidak berpengaruh terhadap kadar air kwetiau tetapi berpengaruh terhadap kualitas masak (waktu pemasakan, berat rehidrasi dan susut masak), kwetiau mentah dan daya putus serta elastisitas kwetiau masak. Sifat fisikokimia bahan baku tepung uwi, tepung talas dan tepung kimpul yang telah dimodifikasi dan tepung beras asli menyebabkan kwetiau yang dihasilkan berbeda karakteristiknya. Karakteristik kwetiau terbaik adalah kwetiau yang terbuat dari tepung beras $100 \%$ dan kwetiau dari tepung talas $100 \%$ mendekati karakteristik kwetiau beras.

\section{DAFTAR PUSTAKA}

Ahmed I., Qazi I.M., Li Z., and Ullah J., 2016, Rice Noodles: Materials, Processing and Quality Evaluation Proceedings of the Pakistan Academy of Sciences: Pakistan Academy of Sciences B. Life and Environmental Sciences 53 (3): 215-238.

Alcázar-Alay S.C., Meireles M.A.A., 2015, Physicochemical properties, modifications and applications of starches from different botanical sources Food Science Technology, Campinas, 35(2): 215-236.

AOAC, 2011, Official methods of analysis of the AOAC, 18th ed. Rev 4. Arlington: Association of official analytical chemists.

Bhattacharya, M., Zee, S. Y., \& Corke, H., 1999, Physicochemical properties related to quality of rice noodles, Cereal Chemistry 76: 861-867.

Cham, S. and Suwannaporn P., 2010, Effect of hydrothermal treatment of rice flour on various rice noodles quality, Journal of Cereal Science 51: 284291.

Chen Z. 2003. Physicochemical properties of sweet potato starches and their application in noodle products, dissertation, Wageningen University. Netherlands.

Fari M.J.M., Rajapaksa D.and Ranaweera K.K.D.S., 2011, Quality characteristics of noodles made from selected varieties of Sri Lankan rice with different physicochemical characteristics, Journal of the National Science Foundation of Sri Lanka 39(1): 53- 60

Fu, B.X., 2008, Asian noodles: history, classification, raw materials, and processing, Food Research International 41: 888-902

Huang, C.C., P. Lai, I.H. Chen, Y.F. Liu, C.R. Wang. 2010. Effect of mucilage on the thermal and pasting properties of yam, taro, and sweet potatoes starch, Food Science and Technology 43: 849-855.

Ismail, M.H., Law, C.L. and Hii, C.L. 2016, Transparency phenomena of flat-rice noodles (kuew teow) at drying at 
soaking variation, International Food Research Journal 23(Suppl): 195-202

Lii, C.Y. and S.M. Chang, 1981, Characterization of Red Bean (Phaseolus radiatus var. auea) starch and its noodle quality, Jounal Food Science 46: 78 -81.

Phothiset, S. and S. Charoenrein, 2007, Morphology and physicochemical changes in rice flour during rice paper production, Food Research International 40: 266-272.

Purwandani L., Indrastuti E., Ramadhia M., 2014, Characteristics of Kwetiau Material of Formulation Rice Flour and Uwi Flour, Taro Flour and Kimpul Flour Modified by Heat Moisture Treatment (HMT), Conference paper International Congress on Challenges of Biotechnological Research in Food and Health November 2014

Qazi I.M, sudip kumar rakshit S.K., theirry Tran T., Javidullah and Khan M.Z., 2014, Effect of blending selected tropical starches with rice flour on the cooking quality and texture of rice based noodles, Sarhad Journal Agricultural 30(2): 257-264

Rais, S.A., 2014, Eksplorasi Plasma Nutfah Tanaman Pangan di Provinsi Kalimantan Barat, Buletin Plasma Nutfah 10(1): 23-27

Rindlav-Westling, A., M. Stading, A.M. Hermansson, P. Gatenholma. 1998. Structure, mechanical and barrier properties of amylose and amylopectin films. Carbohydrate Polymers 36: 217224.

Srichuwong, S., T.C. Sunarti, T. Mishima, N. Isono, and M. Hisamatsu, 2005, Starches from different botanical sources II: Contribution of starch structure to swelling and pasting properties, Carbohydrate Polymers 62: 25-34.

Thao H.M., Noomhorm A, 2011, Physiochemical Properties of Sweet Potato and Mung Bean Starch and Their Blends for Noodle Production, Journal Food Processing Technology 2:105.

Thomas R., T.K. Yeoh, W.A. Wan-Nadiah and R. Bhat, 2014, Quality Evaluation of Flat Rice Noodles (Kway Teow)
Prepared from Bario and Basmati Rice, Sains Malaysiana 43(3): 339347.

Ugarčić-Hardi Z., M. Jukić, D. K. Komlenić, M. Sabo and J. Hardi., 2007, Quality Parameters of Noodles Made with Various Supplements, Czech Journal Food Science. 25 (3): 151-157.

Vatanasuchart N., B. Niyomwit and K. Wongkrajang, 2009, Resistant Starch Contents and the in Vitro Starch Digestibility of Thai Starchy Foods, Kasetsart Journal (Nat. Sci.) 43: 178 186.

Wattanachant S, Muhammad S.K.S, Hasyim D.M., Rahman R.A., 2002, Suitability of sago starch as a base for dual-modification, Songklanakarin Journal Science Technology 24(3): $432-438$ 